\title{
Negative thermal expansion artificial material from iron-nickel alloys by oxide co-extrusion with reductive sintering
}

\author{
J. QI, J. W. HALLORAN \\ Department of Materials Science and Engineering, University of Michigan, Ann Arbor, USA \\ E-mail: john_halloran@engin.umich.edu
}

\begin{abstract}
Objects with a fine-scale design of bimetallic beams can display negative thermal expansion. Based on a unit cell design for a negative expansion, produced by Optimal Design methods, we fabricate a thermoelastic "artificial material" using coextrusion of iron and nickel oxides, followed by reductive sintering. A bulk sample with 162 unit cells from $\mathrm{Fe}-60 \mathrm{Ni}$ and $\mathrm{Fe}-36 \mathrm{Ni}$ alloys displayed a thermal expansion coefficient of $-3.0 \times 10^{-6} /{ }^{\circ} \mathrm{C}$, in agreement with the optimal design prediction. (c) 2004 Kluwer Academic Publishers
\end{abstract}

\section{Introduction}

Most materials expand when they are heated, so they have a positive thermal expansion coefficient. A few materials contract upon heating, so are negative thermal expansion (NTE) materials. Isotropic NTE is known for various materials, such as silicon and germanium [1] at very low temperature, amorphous Y-Fe spin glasses [2], as well as zirconium tungstates family over a broad temperature range [3, 4]. Anisotropic NTE exists in materials like ultradrawn high-density polyethylene [5, 6], carbon and glass fiber [7], INVAR alloy at low temperature [8], $\beta$-eucryptite alumino-silicate family [9], $\mathrm{NbTi}$ at room temperature [10], and some layer crystals like GaS, GaSe and InSe [11]. Currently the fabrication for most of those materials is not available in bulk form with arbitary shape and application temperature of some materials is at very limited range.

Computational design scientists offer another approach to make artificial NTE materials. Sigmund [12] and independently N. Kikuchi and B.-C. Chen [13, 14] designed a NTE artificial material using a three-phase topology optimization method [15]. NTE artificial material is composed by a periodic array of unit cells. The unit cell is made of two different material phases with positive thermal expansion and a void phase. The two materials phases are required to have similar elastic tensors but different thermal strain coefficient tensors. The topology optimization method finds the distribution of materials that achieves the predefined thermoelastic properties subject to certain constraints, such as the volume fractions of different phases in a periodic unit cell. The effective properties of the material which consist of such periodic unit cells can be determined by numerical homogenization method. The design unit and its structure change on heating is illustrated as Fig. 1. It can be seen that the high thermal expansion phase pulls the structure inward to cause the contraction on heating. The design is essentially an elaborate arrangement of bimetallic beams.
This paper reports the realization of the NTE artificial material designs. It can be noticed that there are some weak structures and discrete material distribution in the initial design unit and those features make the design difficult to achieve by most processing techniques. Therefore, we seek an engineering interpretation of the theoretical design by strengthening weak structures with more feasible and stable counterparts and smoothing material distribution while still preserving the basic features in the unit cell. Fig. 2 shows an example of our engineering interpretation of the design unit.

We choose nickel alloy series as the materials candidates for the two materials phases in the design. As shown in Fig. 3, Ni alloy with composition of $36 \mathrm{~mol} \%$ of nickel, well know as INVAR alloy, exhibits an abnormal low thermal expansion compared with other nickel alloy while their elastic modulus are similar [16]. Those characteristics are in line with the requirements of the NTE artificial material and also offer a compatible interface between two material phases.

Microfabrication by coextrusion $[17,18]$ (MFCX) is a new processing technique for fabricating structures with repeat units of sub-millimeter size, which makes it attractive for this repeating unit cells of this artificial material. MFCX is a powder based thermoplastic processing technique. Powders are mixed with thermoplastic polymers to form extrudable compounds. For this case, we use one powder mixture for the high expansion phase, a second powder mixture for the low expansion phase, and a fugitive powder mixture to define the void phase. These are compounded so they have nearly identical rheological behavior at the extrusion temperature. Sections of each compound is molded to have the shape to achieve the design and assembled into a feedrod for a piston-type extruder. The multi-material feedrod is forced through a heated reduction die to reduce the feature size in the coextrusion step. By multiple pass co-extrusion, a large 


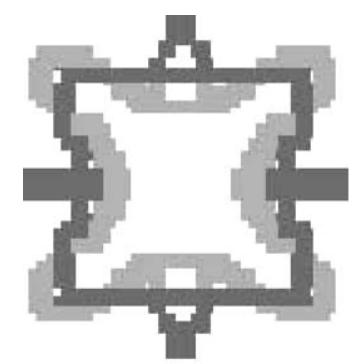

a. unit cell

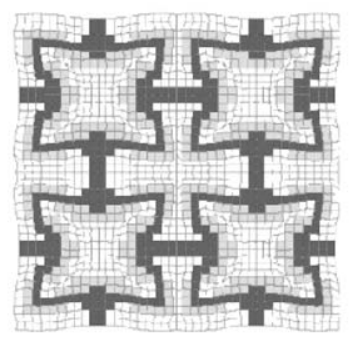

b. structure change on heating
- Low thermal expansion material

- High thermal expansion material

Figure 1 Chen-Kikuchi design for NTE artificial material.

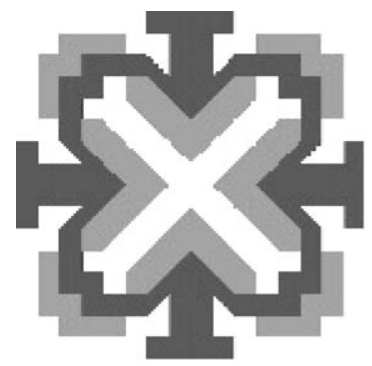

- Low thermal expansion material

- High thermal expansion material

Figure 2 Engineering interpretation of artificial NTE material design.

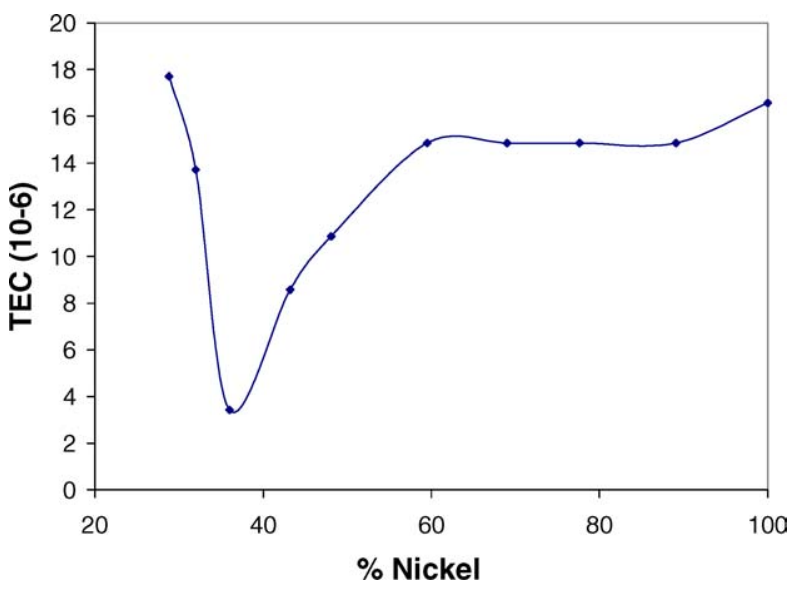

Figure 3 Thermal expansion of Fe-Ni alloy at $300 \mathrm{~K}$.

number repeat units with small feature size can be produced.

Since fine metal powders for nickel and iron is difficult and dangerous to operate in MFCX, a two-step processing route was chosen. First nickel oxide and iron oxide were used to fabricate the NTE artificial material structure by MFCX. Then the structure was reduced to metal from the oxides in a reductive atmosphere. This method was successfully employed to fabricate an artificial material with negative Poisson ratio from nickel [19].

\section{Experimental methods}

Before fabrication of NTE artificial material, it is necessary to study the feasibility of transforming a green body composed of nickel oxide and iron oxide into dense metal alloy. Commercial obtained iron oxide (99\% $\mathrm{Fe}_{2} \mathrm{O}_{3},<5 \mu \mathrm{m}$, Aldrich, USA) and nickel oxide $(99 \% \mathrm{NiO},-325$ mesh, Alfa Aesar, USA) powders were mixed with various compositions of nickel and iron cation ratio in the range of $20-80 \mathrm{~mol} \%$ by ball milling. The step is to improve the material distribution as well as to comminute the particle size. An electrically heated high-density shear mixer (Brabender Corp, Model PL2100, USA) was then employed to create extrudable compounds of powders and thermoplastic polyethylene. Polyethylene resins and processing aids were melted at $120^{\circ} \mathrm{C}$ in the mixer and the powders were combined with the melt.

The compounds then underwent binder burnout to $600^{\circ} \mathrm{C}$ and were sintered at $1050^{\circ} \mathrm{C}$ for $1 \mathrm{~h}$ in a reductive atmosphere ( $10 \%$ hydrogen balanced nitrogen). The shrinkages of green bodies of compounds were measured and X-ray analysis was employed to observe the phase structures of nickel alloy. Thermal expansions of as-sintered nickel alloy were also verified by Thermal Mechanical Analysis (TMA).

We chose $\mathrm{Fe}-36 \mathrm{~mol} \% \mathrm{Ni}$ and $\mathrm{Fe}-60 \mathrm{~mol} \% \mathrm{Ni}$ alloy as material candidates. Three separate thermoplastic compounds were prepared, including oxides compound for $\mathrm{Fe}-36 \mathrm{Ni}$, oxides compound for $\mathrm{Fe}-60 \mathrm{Ni}$ alloy and carbon black fugitive compound for the void. The different compounds were compression molded at $160^{\circ} \mathrm{C}$. Then we shaped the molded thermoplastic compounds as a pattern of simple shapes and assembled them into a feedrod with structure of a quarter of the repeat unit. Uniaxial pressing at $10 \mathrm{MPa}$ and $160^{\circ} \mathrm{C}$ bonded the pieces into a solid block $50 \mathrm{~mm}$ square and about 100 $\mathrm{mm}$ long. This was the first extrusion feedrod. A crosssection of the quarter-design rod appears in Fig. 4a. The black regions are the carbon black-thermoplastic fugitive (which will create the void space). The regions in lighter contrast are the $\mathrm{Fe}_{2} \mathrm{O}_{3}-\mathrm{NiO}$ mixtures for the $\mathrm{Fe}$ $36 \mathrm{Ni}$ and Fe-60Ni materials. Unfortunately these are similar in color, and have poor optical contrast.

The feedrod was extrudated through a symmetric $8: 1$ square reduction die using a piston extruder (Bradford Univ. Research, Ltd., UK). The extrudate had a cross section pattern identical to that of the feedrod, while the dimensions were reduced by a factor of 8 . Four sections of the first extrudate were then bundled together to create the design unit. Nine design units were bundled with short sections connecting them, and combined with additional fugitive and with sheets of the Fe-36Ni oxides compound to create a nine element assembly of interlinked repeat units. The pieces were consolidated under $10 \mathrm{MPa}$ at $160^{\circ} \mathrm{C}$ to create the second feedrod as illustrated at Fig. 5b. After second extrusion, the initial repeat unit had undergone a size reduction of 64 times.

To make the final assembly, 18 sections of the second extrudates were then bundled together and warm bonded to make a solid block containing 156 design repeat units at a density of 56 repeat units per square centimeter. The final assembly was cut into slices with $5 \mathrm{~mm}$ tall. The pieces were fired to $600^{\circ} \mathrm{C}$ in flowing air to remove the binder and fugitive carbon black. After the binder burnout process, the pieces were lightly 


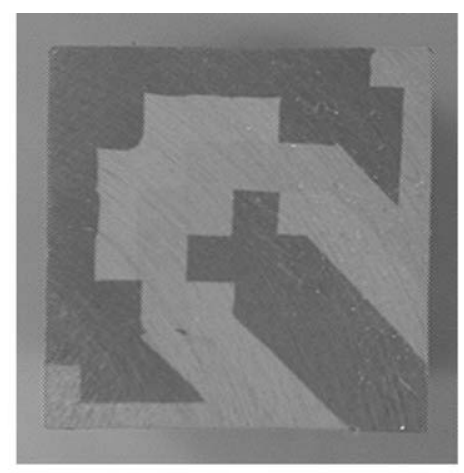

a.Cross section of feedrod for a quarter of design unit

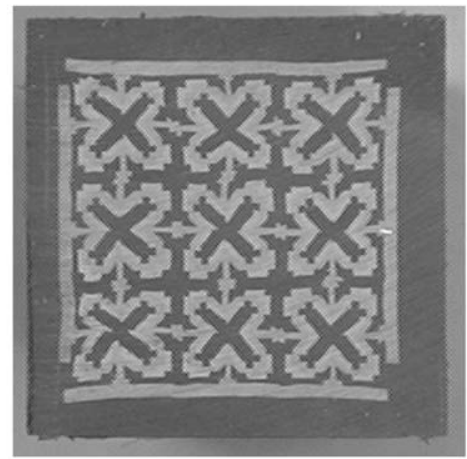

b. Cross section of feedrod for 3 by 3 design units

Figure 4 Thermoplastic extrusion feedrods for NTE artificial material (a) has quarter-design of the design unit as $50 \mathrm{~mm}$ square. The oxide mixtures for the $\mathrm{Fe}-36 \mathrm{Ni}$ and $\mathrm{Fe}-60 \mathrm{Ni}$ materials are similar in color, so have poor optical contrast and (b) is a $50 \mathrm{~mm}$ square feedrod with 9 design units, assembled from 36 extruded quarter-designs.

sintered (bisque-fired) mixtures of iron and nickel oxides. Reductive sintering was done $1050^{\circ} \mathrm{C}$ for $1 \mathrm{~h}$ in an atmosphere of $10 \%$ hydrogen in nitrogen to yield dense Fe-Ni alloy shaped objects.

\section{Results and discussion}

\subsection{Reductive sintering}

Reductive sintering shrinkages of green bodies of oxides compounds after binder burnout were measured. The results are shown as Fig. 5. It can be found that linear shrinkage mismatch between $\mathrm{Fe}-36 \mathrm{Ni}$ and $\mathrm{Fe}-$ $60 \mathrm{Ni}$ alloy are smaller than $1 \%$. Therefore, the NTE architecture will survive after reductive sintering if we choose Fe-36Ni and Fe-60Ni alloy. X-ray analysis was performed to determine the phase of nickel alloy series by a X-ray diffractometer (Rotaflex, Rigaku, Japan) at room temperature. The results are shown in Fig. 7. It can be seen that the nickel alloy made from reductive sintering has $\gamma$-phase (fcc) when the nickel content is above $30 \mathrm{~mol} \%$ and $\alpha$-phase(bcc) when the nickel content is below $30 \mathrm{~mol} \%$. The results are in line with the phase diagram for this system.

Thermal Mechanical Analysis (TMA) was done to measure the thermal expansion coefficients of the nickel alloy series. The samples are $4 \mathrm{~cm} \times 4 \mathrm{~cm} \times 4 \mathrm{~cm}$ cubes made from extrusion compound after binder burnout and reductive sintering. The thermal expansion coefficients are measure at $25-100^{\circ} \mathrm{C}$, as shown in Fig. 7. Experiment results are in line with the thermal expansion data of Tanji [16]. The thermal expansion of Fe-36 $\mathrm{Ni}$ alloy of the INVAR composition is lower than other nickel alloys.

\subsection{Properties and microstructure of NTE artificial materials}

Thermal expansion of NTE artificial material consisting of $3 \times 3$ unit cells was measured by TMA. The result is shown in Fig. 8. The material exhibits a negative linear thermal expansion with thermal expansion coefficient of $-3 \times 10^{-6} /{ }^{\circ} \mathrm{C}$. This can be compared with BingChung Chen's prediction of $-3.2 \times 10^{-6} /{ }^{\circ} \mathrm{C}$. This is based on the modified design of Fig. 2, assuming for

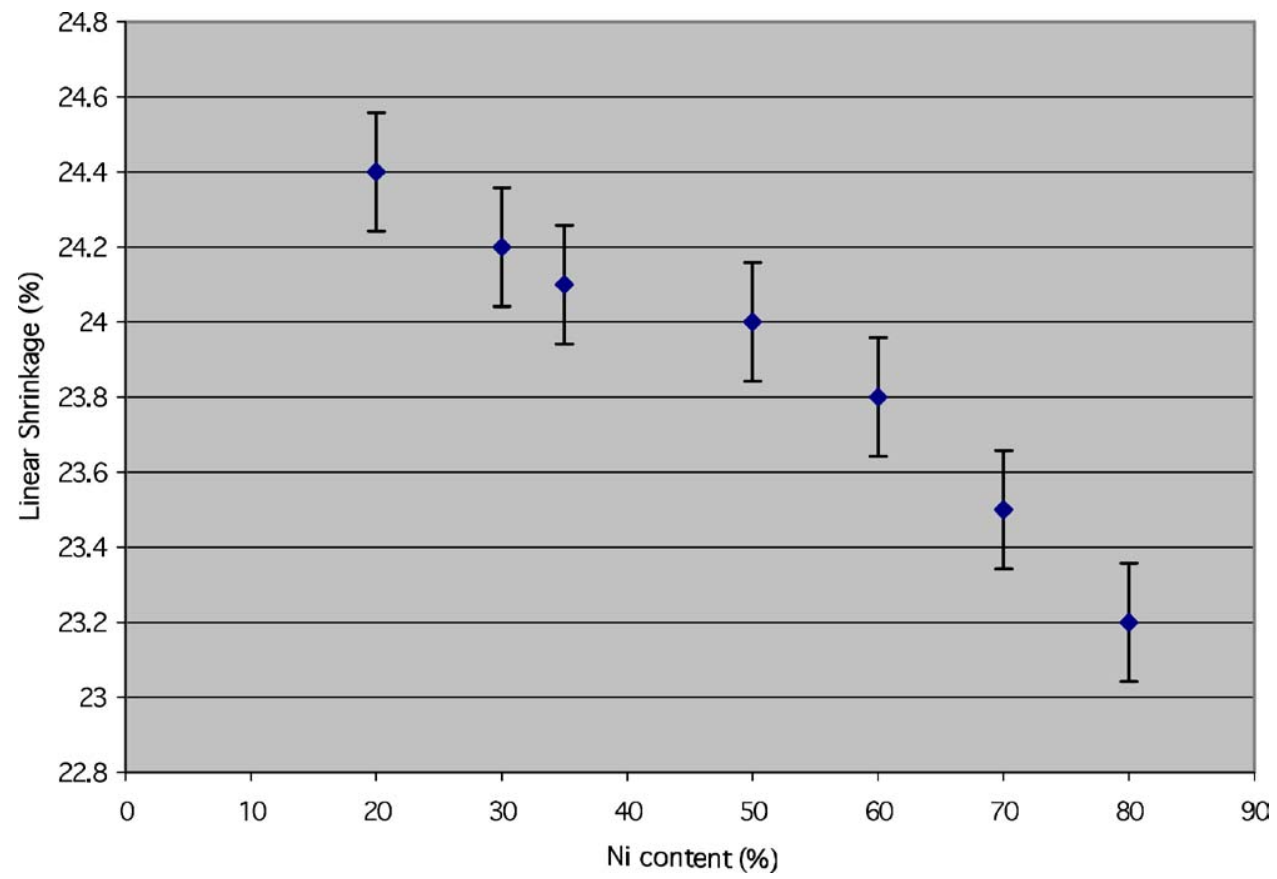

Figure 5 Linear shrinkage after reductive sintering of nickel alloys. 


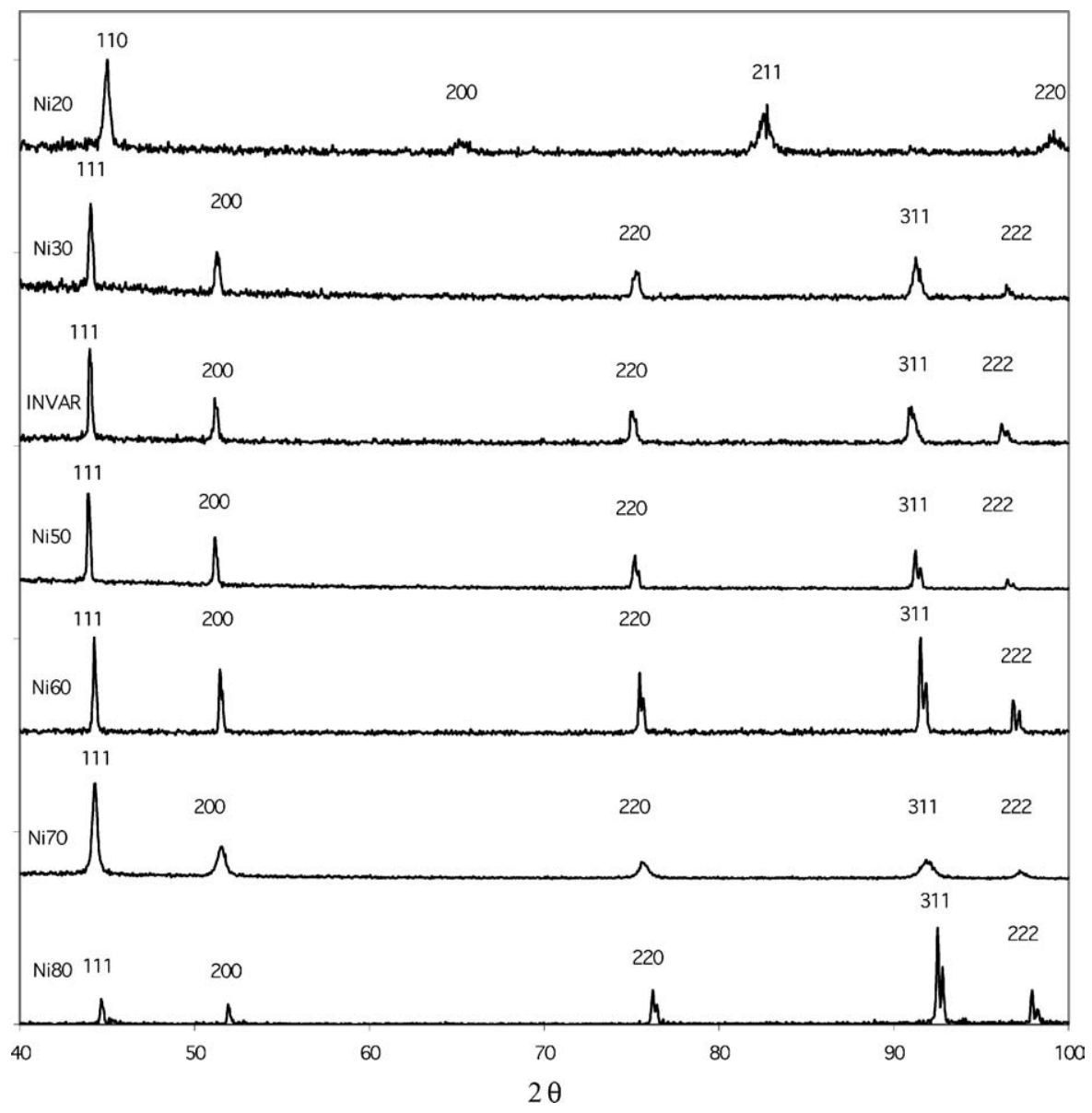

Figure 6 X-ray diffraction of nickel alloys made from reductive sintering of mixed oxides.
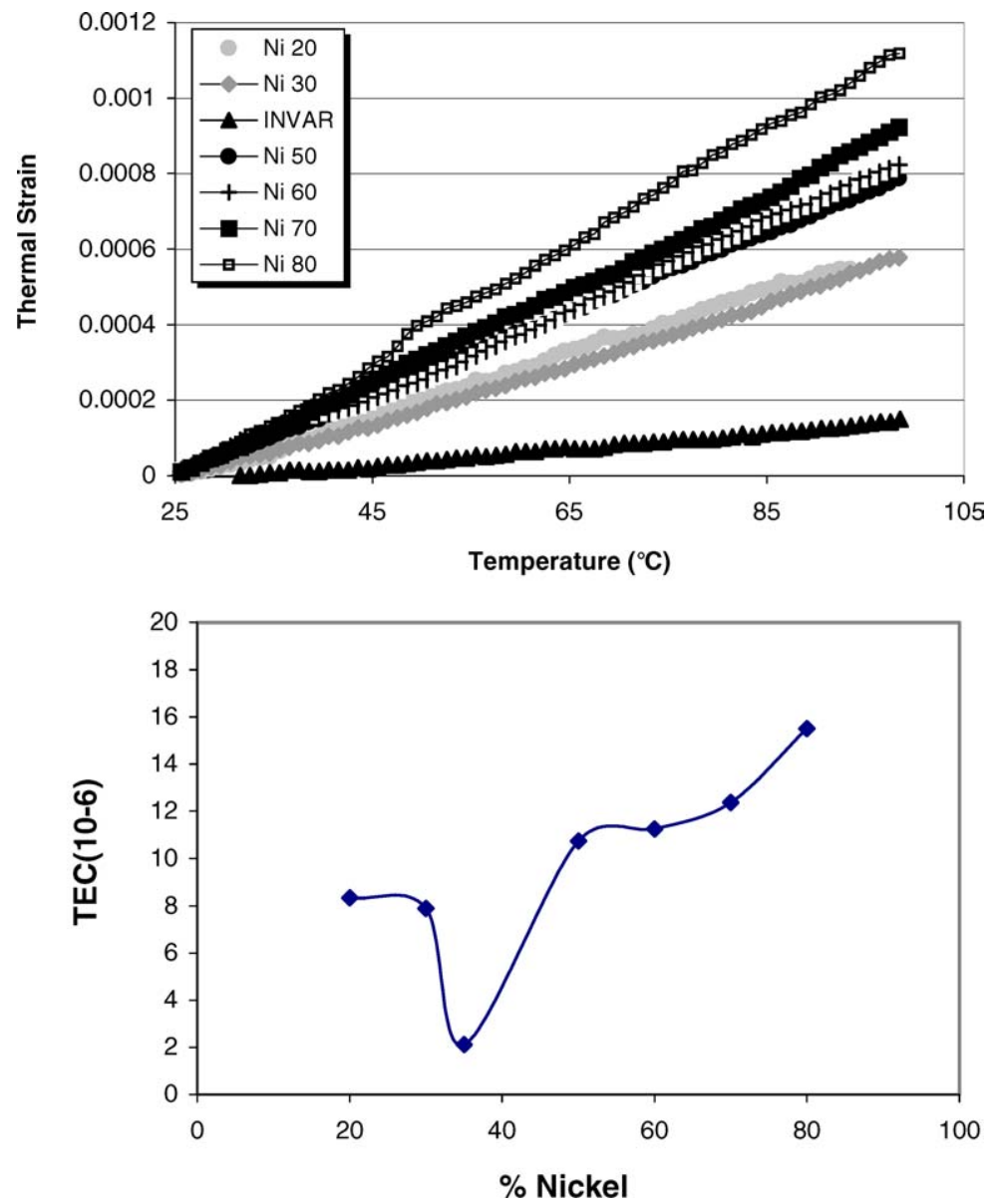

Figure 7 Thermal expansion coefficient of Ni alloy series made from reductive sintering. Top: positive thermal strain vs. temperature for Fe-Ni alloys. Bottom: Thermal expansion coefficient at room temperature vs. composition. 


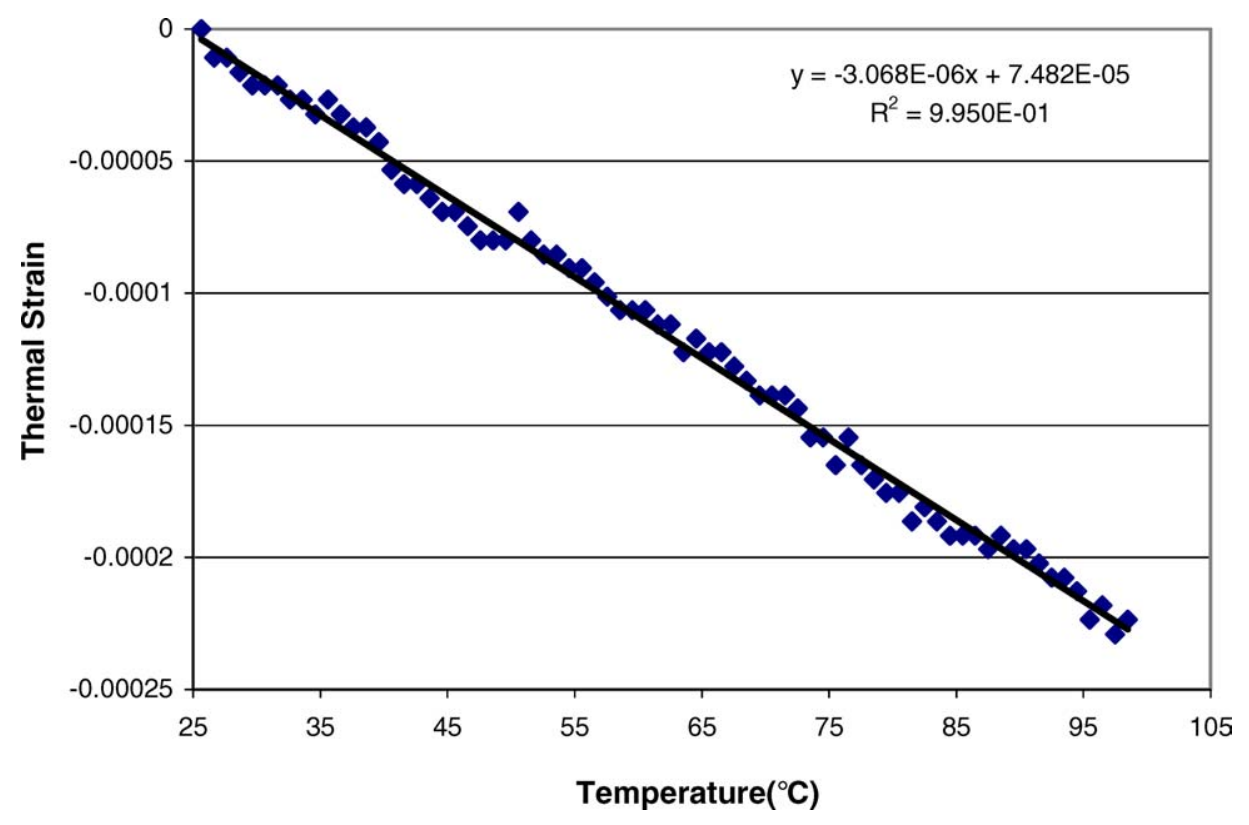

Figure 8 Thermal Strain vs. temperature corresponding to thermal expansion coefficient of $-3.07 \mathrm{ppm} /{ }^{\circ} \mathrm{C}$.

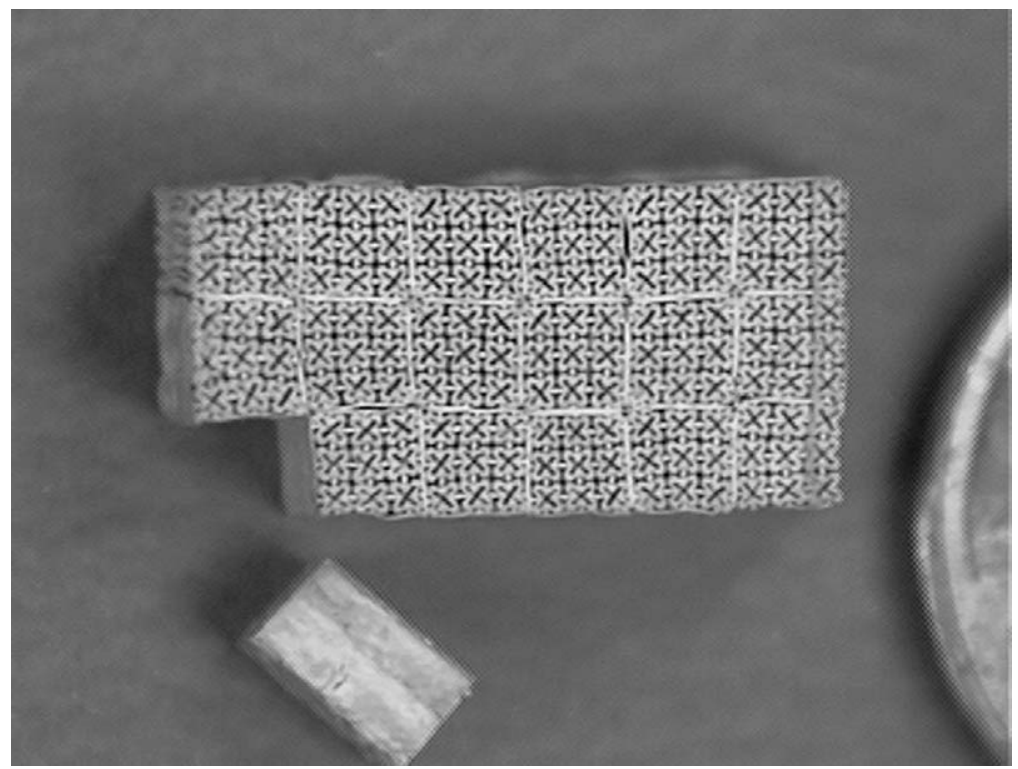

Figure 9 NTE artificial material consisting of 162 unit cells, with 18 blocks having 9 unit cells each. The lower left block has been dislodged to illustrate the assembly. Approximate dimensions are 75 by $150 \mathrm{~mm}$.

the $\mathrm{Fe}-60 \mathrm{Ni}$ an elastic modulus of $160 \mathrm{GPa}$ and thermal expansion coefficient of $+15 \times 10^{-6} /{ }^{\circ} \mathrm{C}$, and for $\mathrm{Fe}$ $36 \mathrm{Ni} 134 \mathrm{GPa}$ and $+3 \times 10^{-6} /{ }^{\circ} \mathrm{C}$. The measured value for the as-fabricated materials is in good agreement with the prediction. Note that this is a two-dimensional design. We expect the thermal expansion coefficient in the third direction to be positive.

Fig. 9 shows a NTE artificial material specimen consisting of 162 unit cells. The specimen consists of 18 blocks, $1.8 \mathrm{~mm}$ square, each containing 9 repeat units (each about $0.6 \mathrm{~mm}$ across). The blocks were sinterwelded during the reductive sintering process, which produced sound bonds in most cases. The block on the lower left has been detached.

Closer examination of a polished surface by SEM (Fig. 10) also shows the structure with unit cell size of $600 \mu \mathrm{m}$ and minimum feature size of $60 \mu \mathrm{m}$. The design has undergone some distortion during co-extrusion

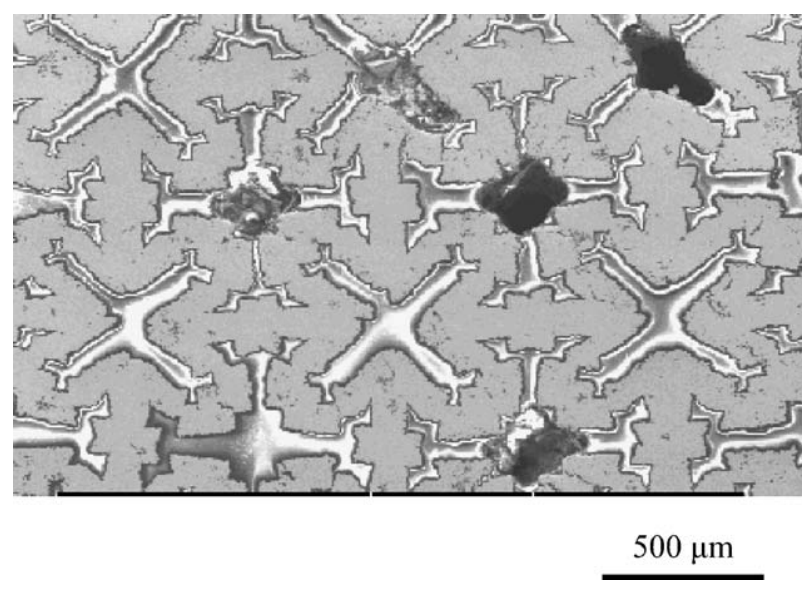

Figure 10 SEM of NTE artificial material unit cell. Cross-shaped features in bright contrast are the designed voids. The $\mathrm{Fe}-36 \mathrm{Ni}$ and $\mathrm{Fe}-60 \mathrm{Ni}$ regions of the bimetallic beams can not be distinguished in this secondary electron image. 
and reductive sintering, but is in reasonable agreement with the design. The bimetallic beams are quite dense. The Fe-36Ni regions cannot be distinguished from the Fe-60 Ni regions in this secondary electron image, but microprobe analysis confirms the anticipated compositions with less than 10 microns of diffusional mixing.

\section{Conclusion}

A bulk sample of an artificial material with negative thermal expansion was fabricated from a complex arrangement of bimetallic beams, generated by an optimal design procedure. The artificial material consisted of a large number of unit cells fabricated in nickel alloy system by the technique of microfabrication by coextrusion to achieve the design in mixed iron and nickel oxides, followed by sintering in a reducing atmosphere. The thermal expansion coefficient was $-3 \times 10^{-6} /{ }^{\circ} \mathrm{C}$, within $10 \%$ of the value predicted for the optimal design. This confirms the design procedure, and the feasibility of negative thermal expansion artificial materials.

\section{Acknowledgement}

The authors thank the Office of Naval Research and Dr. Stephen Fishman for support.

\section{References}

1. H. M. KAGA YA and T. SOMA, Solid State Commun. 85 (1993) 617.

2. T. SUZUKI, A. FIJITA, T. CHIANG andK. FUKAMICHI, Mater. Sci. Engng. A 181/182 (1994) 954.
3. G. ERNST, C. BROHOLM, G. R. KOWACH and A. P. RAMIREZ, Nature 396 (1998) 147.

4. A. W. SlEIGHT, Ann. Rev. Mater. Sci. 281 (1998) 29.

5. N. J. CA Pi A T I, J. Polym. Sci. Polym. Phys. Ed. 151 (1997) 1427.

6. C. L. CHOY, F. C. CHEN and E. L. ONG, Polymer 20 (1979) 1191.

7. M. DE F. F. PINHEIRO, D. J. RADCLIFFE and H. M ROSENBERG, in Proc. of the Int. Cryog. Eng. Conf., 7th London (1978) p. 494.

8. G. HAUSCH, R. BACHER and J. HARTMANN, Physica B $161(1998) 22$

9. J. S. MOYA, A. G. VERDUCH and M. HORTAL, Trans. J. Brit. Ceram. Soc. 73 (1974) 177.

10. D. A. WOODCOCK, P. LightFoOT and R. I. SMITH, Mater. Res. Soc. Symp. Proc. 547 (1999) 191.

11. G. L. BELENKII, E. YU. SALAEV, N. A. SULEIMANOV, N. A. ABDULLAEV and V. YA. S HTE IS HR A I B E R, Solid State Commun. 53 (1985) 967.

12. O. Sigmund and S. TORQuAto, J. Mech. Phys. Solids 45 (1997) 1037.

13. B ING-CHUNG CHEN, "Optimal Design of Material Microstructure and Optimization of Structural Topology for Design-Dependent Loads," Ph.D. Thesis, Mechanical Engineering, University of Michigan, 2000.

14. BING-CHUNG CHEN, EMILIO C. N. SILVA and N. KI K UCHI, Intern. J. Numer. Meth. Engng. 52 (2001) 23.

15. M. P. BENDS $\varnothing \mathrm{E}$ and N. KIKUCHI, Comp. Meth. Appl. Mech. Engng. 71 (1988) 197.

16. Y. T A NJI, J. Phys. Soc. Japan 31 (1975) 1366

17. C. VAN HOY, A. BARDA, M. GRIFFITH and J. W. HAllor An, J. Amer. Ceram. Soc. 81 (1998) 152.

18. A. T. CRUMM and J. W. HALLORAN, ibid. 81 (1998) 1053.

19. A. T. CRUMM, "MicroFabrication by Coextrusion," Ph.D. Dissertation University of Michigan, 2000.

Received 11 September 2003

and accepted 24 March 2004 